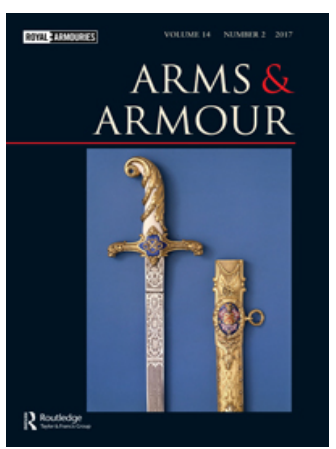

Arms \& Armour

\title{
An Investigation of the Weights of Pattern 1907 Bayonets made in the UK around the First World War Period
}

\section{John M. Ballard \& Julian Bennett}

To cite this article: John M. Ballard \& Julian Bennett (2017) An Investigation of the Weights of Pattern 1907 Bayonets made in the UK around the First World War Period, Arms \& Armour, 14:2, 206-222, DOI: $10.1080 / 17416124.2017 .1379786$

To link to this article: https://doi.org/10.1080/17416124.2017.1379786

\section{Published online: 23 Oct 2017.}

Submit your article to this journal $\sqsubset$

Џ Article views: 92

View Crossmark data $\complement$

4

Citing articles: 1 View citing articles $\square$ 


\section{An Investigation of the Weights of Pattern 1907 Bayonets made in the UK around the First World War Period}

JOHN M. BALLARD

Independent Researcher, St. Augustine, FL, USA

JULIAN BENNETT

Department of Archaeology, Bilkent University, Ankara, Turkey

The standard issue bayonet of the British Army immediately preceding and during the First World War was the Pattern 1907. This was manufactured at different times and in varying numbers during that period by one official body, the Royal Small Arms Factory at Enfield, and by five private contractors. These bayonets were made according to published official specifications issued by the War Department and based on a 'pattern example' provided by the Royal Small Arms Factory. The specifications indicate, inter alia, the quality of metal used in making the bayonets, methods of inspection and proofing, and the required maximum and minimum weight range of the completed bayonet. However, examination of a series of these bayonets in a private collection suggested that their weights varied considerably from the mid-point values of the allowed weight ranges in the original and amended specifications $(16.5 \mathrm{oz}$. and 17 oz., respectively). To establish if this was a common feature among this class of bayonet as opposed to a chance factor, the weights of other surviving Pattern 1907 bayonets were determined and compared to establish the degree of variance from the official specifications as originally set out by the Royal Small Arms Factory. Seventy-six percent of the 142 bayonets surveyed were found to be above the mid-point of the allowed weight range given in the amended manufacturing specifications, with many being at the upper end of the allowed range. This is a statistically unusual result. It is speculated that the target weight may have been deliberately set higher by the individual manufacturers to eliminate the possibility of rejection of any underweight bayonets by the Royal Small Arms Factory inspectors and so a refusal of acceptance and payment for the work. 
KEYWORDS bayonet, Pattern 1907, weights, First World War, statistical analysis.

\section{Introduction}

The standard issue bayonet of the British Army immediately preceding and during the First World War, and for a considerable time after, was that described in the official records as the 'Sword-bayonet, Pattern I907 (Mark I)'. This was designed originally for fixing to the recently introduced 'Short, Magazine, Lee-Enfield rifle' (SMLE), and was approved for service use on 30 th January I908. ${ }^{\mathrm{I}}$ As described in the official Specification No.S.A./3I9, Sword-bayonet, Pattern 1907 (Mark I) for Rifles, short, M.L.E. as approved on 9th March, I908, it consisted of a one-piece, steel blade and tang, the manufacturing specifications requiring an allowed blade length range of I6.875-I7.I25 in. (429-435 mm) and an allowed overall length range of $2 \mathrm{I} .655^{-21.935} \mathrm{in} .(550-558 \mathrm{~mm}) .^{2}$ This blank was given a crossguard, ${ }^{3}$ with an upper opening for the boss on the nose-cap of the rifle and with a lower hooked quillon and a pommel, both of these parts made of wrought iron or mild steel and which were brazed onto the tang. A wooden grip (walnut was specified) was placed on each side of the tang and secured by a pair of machine screws passing through holes drilled in the tang, fixed with nuts on the opposite side. A shallow groove known as a fuller was machined on each side of the blade to reduce weight whilst maintaining rigidity. In accordance with the original manufacturing specifications, the allowed weight range of the finished bayonet was initially I5.5-I7.5 Oz. (439-496 g). ${ }^{4}$ This was subsequently changed to I $6-\mathrm{I} 8 \mathrm{oz}$. $(454-5 \mathrm{IO} \mathrm{g})$ as indicated in the revised specifications of I9IO and I9I $4 .{ }^{5}$ During the final stages of manufacture the bayonet received a series of official stamps on the flat part of the blade at its junction with the crossguard. Those on the right flat included an ' $\mathrm{X}$ ' bend-test mark, a War Department arrow, and one or more Royal Small Arms Factory (RSAF)-appointed inspector's marks; those on the left flat consisted of the reigning monarch's crown and cypher (ER for Edward VII until May of I9Io, and GR for George V from May of I9Io until January of I936), the date of the bayonet's official inspection and approval for service (in a numerical month/year format), and the name of the maker.

The Pattern 1907 (hereafter Patt. I907) bayonet arose from trials in 1906-1907, following concerns that the reach of the new SMLE rifle and its Pattern I903 (Patt. 1903) bayonet was too short for effective combat use. At this time, the view prevailed that a long reach was required for effective one-on-one bayonet duels with an enemy. ${ }^{6}$ However, the overall length of the SMLE rifle and the Patt. 1903 bayonet (about I.45 m) ${ }^{7}$ was significantly shorter than that of the French Mle. I886 'Lebel' rifle and bayonet (about I.82 m) ${ }^{8}$ and even that of the German Gew.r898 rifle and bayonet (about I.77 m). 9 The trials resulted in the British army developing and then adopting their own version of the Japanese Type 30 Arisaka bayonet of I897, this becoming the Patt. 1907 as was described in the List of Changes, para. I4I70 of 30 January I908; the combined length of the SMLE rifle and the Patt. 1907 bayonet was then approximately I. $57 \mathrm{~m} .{ }^{\text {I0 }} \mathrm{In}$ its first incarnation, 
shown full-length in Figure I(a), it retained the hooked quillon of the Japanese Type 30 , as seen in the close-up view of the hilt area given in Figure $\mathrm{I}(\mathrm{b})$. It is popularly believed that this was to assist in direct combat with an enemy soldier. In theory, or so we are told, it allowed a rifleman to catch an opponent's bayonet and so at the very least parry an incoming thrust, if not actually enabling him to wrest away his opponent's bayonet and rifle. However, on 29 October I9I3, the decision to produce the bayonet with a simpler crossguard without the hooked quillon was published. ${ }^{\text {II }}$ Unit armourers often subsequently removed the hooked quillon from bayonets in service when they went in for repair, although there is as yet no evidence that this was ever required on an official basis. Thus, it is not known if the hooked quillon was deemed simply unnecessary, or if this was removed as a cost-cutting measure.

Another change to the design of the Patt. 1907 bayonet, namely the provision of a clearance hole in the pommel, was ordered during the First World War period itself in January I9I6. ${ }^{\text {I2 }}$ Practical experience of using bayonets with the mortise-and-bar method of fixing these to a rifle had shown how easy it was for the mortise of the bayonet to become clogged with debris. Hence this feature had been provided in the hilt of the earlier

(a)

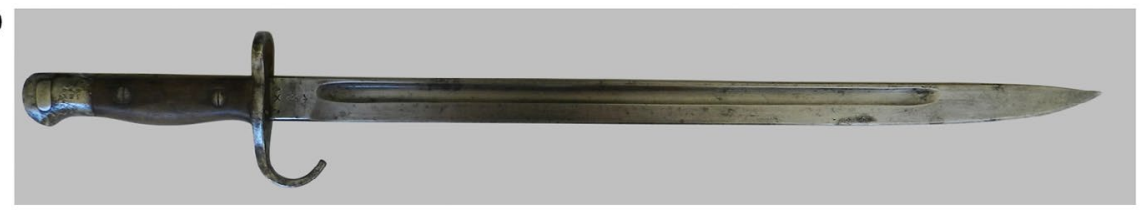

(b)

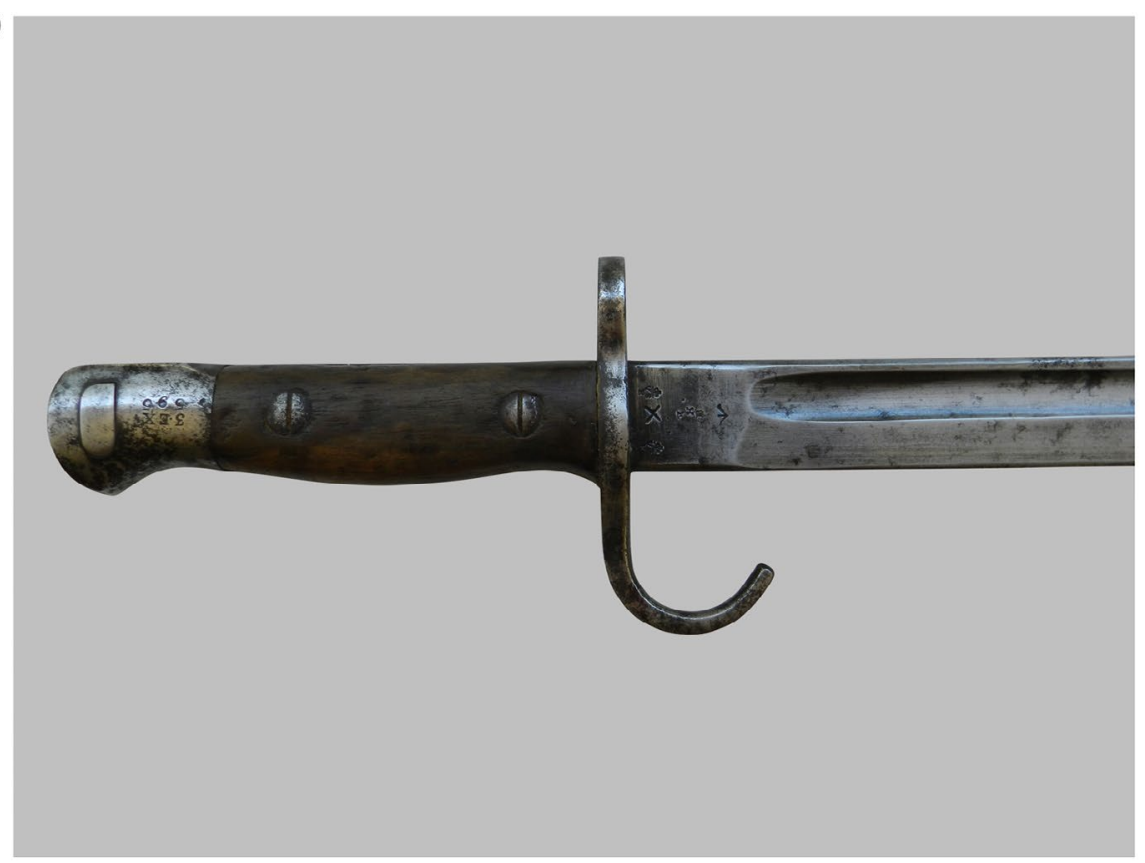

FIGURE 1. (a) Patt. 1907 bayonet with hooked quillon and without clearance hole, (b) Close-up of hilt of Patt. 1907 bayonet with hooked quillon and without clearance hole. 
Pattern I888 (Patt. I888) Mk. I bayonet, and in the pommel of the Patt. I888 Mks. II and III and the Patt. I903 bayonet. Quite why the original version of the Patt. I907 did not have this feature is unclear, although it is noteworthy that this feature is also absent from the Japanese Type 30, hinting that the Patt. 1907 was a clone of this in more ways than one. Be that as it may, sustained service use in field conditions in the early part of the First World War evidently highlighted the absence of a clearance hole and so the decision was made to supply one. As shown in Figure 2, the matter was resolved by drilling a small clearance hole right through the pommel, very close to the wooden grips, to enable debris to be pushed out. That the notification regarding the addition of a clearance hole to older Patt. I907 bayonets was not strictly adhered to, is demonstrated in several instances. For example, the absence of a clearance hole from such a bayonet dated ' 03 Io' and which has a succession of re-inspection marks leading up to, and including one for, '(I9) '4I'. ${ }^{\text {I3 }}$

The Patt. I907 bayonets of the First World War period available for study today, therefore, include those that still retain the hooked quillon, those that were made with this feature but which was subsequently removed, those that were made without a hooked quillon, those of all three of these versions that were later given a clearance hole and those that were made without a hooked quillon and with a clearance hole. In surveying the weight variations in all of these classes of bayonets, all of these attributes have to be noted. Because the hooked quillon and the pommel are both made of mild steel or wrought iron, removing either the hooked quillon or drilling a clearance hole should reduce the weight of such a bayonet compared to an unmodified one, by about I4 $\mathrm{g}$ in total (about 0.5 oz.; see Methodology). In the List of Changes that introduced the Patt. I907 bayonet (with hooked quillon, but without clearance hole), it is described as having a weight of I6.5 Oz., a maximum blade length of $\mathrm{I} 7$ and I/ $8 \mathrm{in}$. and a length overall of $2 \mathrm{I}$ and I5/I6 in. ${ }^{\mathrm{I} 4}$ The weight is clearly the mean (arithmetic average) of the low and high values as given in the initial manufacturing specification, that is to say, Specification No. S.A./3I9, Sword-bayonet, Pattern I907 (Mark I) as approved 9 March, I908; the length

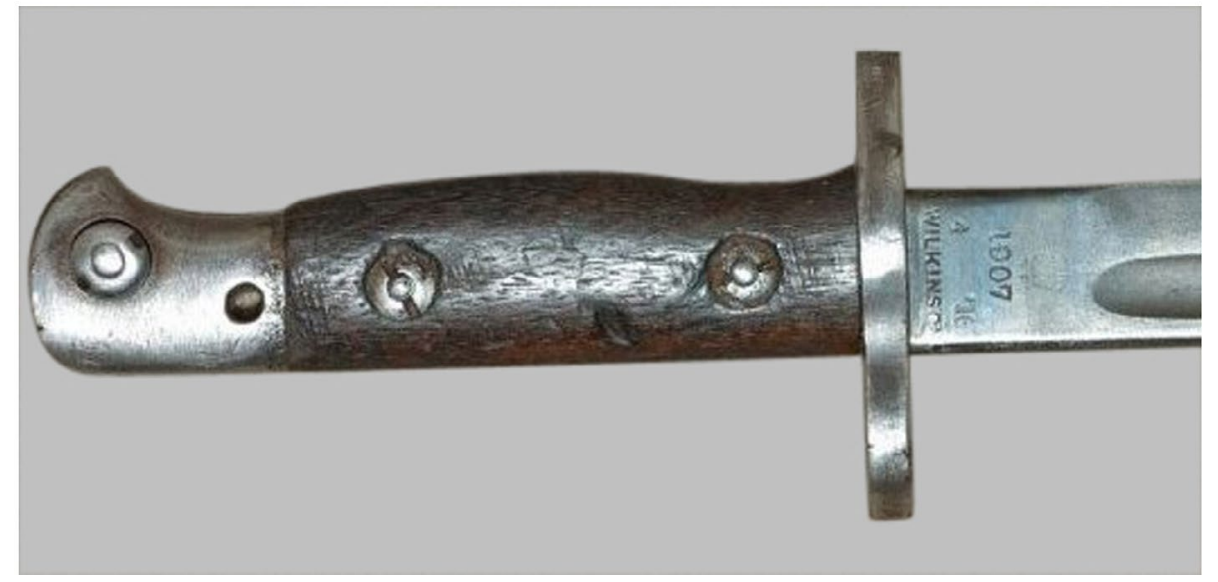

FIGURE 2. Close-up of hilt of Patt. 1907 bayonet without hooked quillon and with clearance hole. 
dimensions by contrast are the exact maximum values as provided in the full-size and annotated drawing 'A.I.D./527/A' as attached to that manufacturing specification.

It is thought likely that the weight was a result of the design requirements (length, width, flexibility etc.) rather than an inherent value. Certainly the weight of a bayonet was of concern, both with the overall equipment load on a soldier and also the effect on the balance and possibly on the accuracy of the SMLE rifle. Interestingly enough, the Text Book of Small Arms, a British War Office publication of I929, which contains a summary of the manufacture and inspection of the Patt. 1907 bayonet, while not detailing its specifications as such, gives the weight as between I6 oz. and I 8 oz. (454 and 5 IO g). ${ }^{\text {I5 }}$ These numbers are obviously the low and high values from the revised manufacturing specification of I9I0 and onwards. ${ }^{\mathrm{I}}$

The arguments presented in this paper are based on the mid-point I6.5 oz. (468 g) of the allowed weight range as given in the original specifications issued in I908, the relevant List of Changes entry, and the range mid-point weight of I7 oz. (482 g) as introduced in the revised specifications of I9IO and I9I4. This seems to be a reasonable approach given how in the first instance, those bayonet-makers contracted to make Patt. I907 bayonets after I9I0 would presumably strive to make specimens close to the minimum weight allowed by the current specification, which was raised at that time to I6 oz. (453 g) from an origina 5.5 oz. (439 g); and that the I929 Text Book of Small Arms states that bayonets were inspected and gauged throughout the manufacturing process. ${ }^{17}$ Indeed, as that document noted, using parallel terms to what was stated in the original I908 and the I9Io and later specifications, 'If one-fourth of any delivery is found inferior to the sealed pattern, or contrary to the terms of the specification governing manufacture, the whole consignment is liable to rejection. ${ }^{18}$ This seems to imply that underweight, as well as overweight, bayonets could be rejected. The issue of meeting an exact weight specification or even a weight range is described in the I929 publication only as 'The completed bayonets are weighed ...' ${ }^{19}$

Given the official specifications and strictures as reviewed above, it seemed remarkable to the authors that the weights of the Patt. 1907 bayonets in a private collection all proved to be somewhat above the mean weight of $16.5 \mathrm{oz}$. (468 g) as indicated in the List of Changes, and certainly well above the minimum weight standard as set out in the official specifications of 1908 or as amended in I9IO and not changed in subsequent issues. This at first sight could be explained by their being made by different manufacturing concerns. However, enquiries among other collectors established that this collection was not an 'exception to the rule'; other collections likewise contain Patt. I907 bayonets that are 'overweight' with regard to what was to be expected according to the official specifications. Thus the decision was made to acquire the weights of more Patt. I907 bayonets from a variety of sources to determine if this 'overweightness' was a consistent, or an incidental, feature of these bayonets. If the former, it was hoped to establish what this might mean in terms of the quality control of the production of these weapons. 


\section{Methodology}

The sources of data for this survey include examples held in private collections, one museum collection and many on-line sellers. The anticipated value of using examples from the one museum and on-line sellers was the inherent belief that these were probably less likely to suffer from an inadvertent collector bias, in the sense of such examples perhaps having been chosen from a collector's preference for an 'overweight' rather than a standard weight bayonet. What was requested from each source was the weight of individual bayonets as determined on a 'reasonably accurate scale' in either grams (g) or ounces (oz.), along with the name of the manufacturer, together with the presence or absence of the hooked quillon in the case of bayonets made before November I9I 3 ; the presence or absence of a clearance hole on bayonets made after January I9I6; and the overall condition of the blade and fittings. Weights reported in ounces were converted to grams, using I oz. $=28.35 \mathrm{~g},{ }^{20}$ and were rounded to whole numbers using the normal mathematical convention. Comparative analysis, using a typical density of steel as $7.9 \mathrm{~g} /$ $\mathrm{mL}^{2 \mathrm{I}}$ suggests that drilling a clearance hole removes approximately $2.8 \mathrm{~g}$, and deleting the hooked quillon removes approximately II.4 g; the total is about I4.2 $\mathrm{g}$, which is about $0.5 \mathrm{oz}$. As it was thought that the type of steel might play a role in any variations of weight, bayonets from the various makers of the Patt. I907 based outside of the UK (Ishapore, India; Lithgow, Australia; Remington Arms, USA) were therefore excluded from the study.

The use and aging of roo year-old bayonets can result in rusting (ranging from pitting to flaking) of the iron and steel components. For this reason, the weights of heavily corroded bayonets are not included in the study. Prolonged and heavy use can also result in the loss of wood from the walnut grips. To allow for this factor, the weight of an original pair of grips (unused old-stock I942/I943) was established as being I7 g. ${ }^{22}$ Because the loss of even an entire quarter of one grip would only, on average, be equivalent to approximately $2 \mathrm{~g}$, the condition of the grips of the bayonets that were surveyed were not taken into account in our initial survey. However, observation of photographs of most of the bayonets used in this survey, and of a much larger number surveyed for another purpose, showed that none had more than small chips or gouges of the grips. This meant that all differences in weight were essentially due to variations in weight of the iron and steel components.

The data analysis for this paper was generated using Microsoft Excel (20I0) spreadsheets with the Real Statistics Resource Pack software (Release 4.3). Copyright (20I320I5) Charles Zaiontz; www.real-statistics.com.

\section{Results and Discussion}

Six British manufacturers made Patt. I907 bayonets during the First World War. They are in alphabetical order, J. A. Chapman Ltd., Royal Small Arms Factory (Enfield), R. Mole \& Sons, Sanderson Bros. \& Newbould Ltd., Vickers Ltd. and Wilkinson Sword Co. Ltd. Estimated production numbers for these makers are given in Table $\mathrm{I}^{23}$ 
From the data given in Table $\mathrm{I}$, it was anticipated that the surviving bayonets would be heavily dominated by those made by Wilkinson and Sanderson, together with a limited number of those made by Chapman and at Enfield; the relatively low production numbers of Mole and Vickers promised that these makers would be poorly represented. This is confirmed by Table 2 , which presents a listing of the weights of bayonets made by a given maker and obtained by the survey. In that table, HQ indicates that the hooked quillon is present, HQR indicates that the hooked quillon has been removed and a number in parentheses indicates the number of bayonets of that configuration and weight. Unless otherwise noted by an asterisk (*), all of the bayonets listed here have a clearance hole drilled through the pommel, and it can be seen that several made before October I9I 3 did not have their hooked quillon removed, while a number made before January I9I6 subsequently escaped being provided with a clearance hole. It will moreover be seen that some bayonets avoided both modifications.

An obvious conclusion from a visual inspection of the data sets is that all the makers of Patt. I907 bayonets had produced bayonets that were essentially similar in overall terms of their weight. This of course was the purpose of the government contract: the bayonets should conform to the official specifications as set by the RSAF at Enfield. Because each bayonet from each maker had to pass a stringent bending test without deforming or breaking, it is possible that each maker used steel of the same or very similar formulation, possibly from the same supplier. As it is, in addition to specifying the composition of the metal 'recommended' for use, the original I908 specifications clearly state (para. 8) that 'All steel employed must be manufactured from Swedish or other high class approved ores only', a statement that was parroted in the I9Io and subsequent specifications. In which case, then assuming the specified steel quality and composition was in fact used, the major variable in the process of making the necessary number of Patt. 1907 bayonets was the skill of the operators involved in the machining and milling processes. Not unnaturally, this resulted in bayonets that were very similar in appearance, but not identical in weight, although all things considered, the weights would be roughly the same regardless of who did the final finishing.

As even a cursory examination reveals, there are several surprising features of the data presented in Table 2. First, and most striking, is that Io8 values (approximately $76 \%$ ) are above the mid-point (I7 Oz.; $482 \mathrm{~g}$ ) of the weight range given in the I929 Text Book of Small Arms; this leaves approximately $24 \%$ at or below the mid-point. This $3:$ I ratio in favour of the higher weights would not be expected statistically to occur.

One possible explanation for the preponderance of 'overweight' bayonets is that the heavier the bayonet, the better its chances of war-time survival so that the bayonets documented here are the result of a 'survival of the fittest' type of self-selection. This

TABLE 1.

ESTIMATED PRODUCTION NUMBERS OF PATT. 1907 BAYONETS BY MAKER

\begin{tabular}{lcccccc}
\hline Maker & Chapman & Enfield & Mole & Sanderson & Vickers & Wilkinson \\
\hline Production & 300,000 & 500,000 & 60,000 & $1,600,000$ & 10,000 & $2,360,000$ \\
\hline
\end{tabular}


is, of course, impossible to determine today. Only in the case of unit-marked Patt. 1907 bayonets, which are not common artefacts, is it possible to say if a particular bayonet was issued to a First World War-period unit; even then it may not have seen actual service use. We simply have no idea which, if any, of the bayonets listed in Table 2 were actually used in a theatre of war. All that can be said in this regard is that, by studying examples offered from a variety of sources, we believe that any possible collector bias of favouring heavier over lighter examples of these bayonets for personal collections is unlikely to have any significant effect on the overall data presented here.

Another possible explanation for the significant number of 'overweight' bayonets reported in our survey is that the manufacturers deliberately produced bayonets that well exceeded the mid-point of the allowed weight-range specification. As is made clear in the official 1908 specifications and their later amendments, 'If one fourth of any delivery' of finished bayonets 'be inferior to the sealed pattern or contrary to the terms

TABLE 2.

WEIGHTS (G) OF INDIVIDUAL BAYONETS BY MAKER

\begin{tabular}{|c|c|c|c|c|c|}
\hline Chapman & Enfield & Mole & Sanderson & Vickers & Wilkinson \\
\hline 456 & $456^{*} \mathrm{HQ}$ & 473 & 440 & 454 & 478 \\
\hline 466 & $476 \mathrm{HQR}$ & 479 & 454 & 461 & 479 \\
\hline $479{ }^{\star} \mathrm{HQ}$ & 476 & 483 & 470 & 480 & 480 \\
\hline 482 & $479 \mathrm{HQR}$ & 485 & $471^{*} \mathrm{HQ}$ & 484 & $482(2)$ \\
\hline 485 & $479^{\star} \mathrm{HQ}$ & 486 & $471(2)$ & 488 & 485 \\
\hline $490(2)$ & 480 & $496 * \mathrm{HQ}$ & 478 & $489(2)$ & 488 \\
\hline 494 & 481 & 505 & 480* HQ & 490 & 490 \\
\hline $495^{\star} \mathrm{HQ}$ & 482(3) & & $480 * \mathrm{HQR}$ & 497 & 491 \\
\hline 505 & 485 & & $480 \mathrm{HQR}$ & & $492^{*} \mathrm{HQR}$ \\
\hline 511 & 486 & & $482(4)$ & & 493(3) \\
\hline \multirow[t]{23}{*}{$524^{*}$} & $489^{*} \mathrm{HQR}$ & & 485 & & 494 \\
\hline & $491^{*} \mathrm{HQ}$ & & 486 & & 496(3) \\
\hline & $500 * \mathrm{HQ}$ & & $487^{*} \mathrm{HQ}$ & & $497^{\star} \mathrm{HQ}$ \\
\hline & 510 & & 488(3) & & $498^{\star} \mathrm{HQ}$ \\
\hline & & & 490 & & 498 \\
\hline & & & 492 & & 499(2) \\
\hline & & & 493 & & $500(3)$ \\
\hline & & & $494^{*} \mathrm{HQ}$ & & $502(2)$ \\
\hline & & & $494(2)$ & & $504(3)$ \\
\hline & & & $496(2)$ & & $505(2)$ \\
\hline & & & 497 & & $506^{\star}$ \\
\hline & & & $498^{*} \mathrm{HQ}$ & & $507(3)$ \\
\hline & & & 498 & & $508(2)$ \\
\hline & & & 499(4) & & $510 * \mathrm{HQ}$ \\
\hline & & & $502(2)$ & & $512(2)$ \\
\hline & & & 504 & & $513^{*} \mathrm{HQ}$ \\
\hline & & & $505(2)$ & & $513(3)$ \\
\hline & & & 507 & & 516 \\
\hline & & & $510(5)$ & & $524(2)$ \\
\hline & & & 514 & & \\
\hline & & & 518 & & \\
\hline & & & 528 & & \\
\hline & & & 532 & & \\
\hline
\end{tabular}

Notes: Numbers in parentheses denote number of bayonets of that weight and configuration; *denotes a bayonet that does not have a clearance hole; HQ denotes that the hooked quillon is still present; HQR denotes that the hooked quillon has been removed. 
of this Specification, the whole consignment will be liable to rejection', this same 'one fourth' limitation being repeated in the I929 Text Book of Small Arms. Thus, the various manufacturers may have deliberately made their bayonets overweight to avoid the possibility of a consignment being rejected simply because $25 \%$ were underweight. Aside from any immediate financial considerations in not being paid for this rejected work, this would have caused a major shortfall and delay in production, and an enormous recycling effort of the underweight bayonets. It is reported that manufacture of the Patt. I907 bayonet with hooked quillon in Australia required I46 operations ${ }^{24}$ and we can reasonably assume a lower, but similar number for the non-hooked quillon bayonet. Given that bayonet manufacture was so labour-intensive, it is surmised that such a loss of production during war-time would have been especially unacceptable to the War Office and to the manufacturers also, who quite possibly risked having their contracts cancelled as a result. Be that as it may, a second striking aspect of the data is the wide range of reported values returned for each of the major makers. These variations for each data-set are summarised in Table 3.

How then to account for the significant overweight variations observed in this study of bayonets made by a number of makers? On average, only $3.5 \%$ of the weight of an individual bayonet is in the wooden grips; as noted earlier, loss of even one-quarter of a grip would only lower the weight by an average of approximately $2 \mathrm{~g}$. In which case, the large weight variations are clearly due to differences in the steel or wrought iron components, ten of which go into the production of a finished Patt. 1907 bayonet. They are (a) a single-piece blade and tang, (b) a crossguard, (c) a pommel, (d) a bolt, spring and nut that fit into the pommel, and (e) two pairs of machine screws and nuts. The items listed above in (d) and (e) range in size from small to very small and cannot be responsible for the large weight variations. The pommel and the crossguard fit very tightly onto the tang, brazed into place and again, the relatively small amount of brass used cannot be the cause of excess weight. The tang is of uniform thickness, with one straight edge and one recurved edge, and again is unlikely to be responsible for the weight variations. As for the standard crossguard from a post-I9I5 Patt.I907 bayonet, this is estimated to weigh approximately $40 \mathrm{~g}$, while the pommel is estimated to weigh approximately $88 \mathrm{~g}$. A significant and very visible distortion of the dimensions of the crossguard or the pommel, or both, would have been required to generate a weight increase of more than a few grams.

The blade, therefore, has to be the major source of variability in the weight of the bayonet. Not only is this conclusion reached by the process of elimination described above, but it is also derived readily by the visual inspection of any Patt.I907 bayonet. The

TABLE 3.

SUMMARY STATISTICS OF SAMPLED BAYONET WEIGHTS (G) BY MAKER

\begin{tabular}{lrrrrrr}
\hline Maker & Chapman & Enfield & \multicolumn{1}{c}{ Mole } & Sanderson & Vickers & Wilkinson \\
\hline Count & 12 & 16 & 7 & 50 & 9 & 48 \\
Mean $(M)$ & 489.8 & 483.4 & 486.4 & 493.0 & 481.3 & 500.5 \\
Std. Dev. $(\sigma)$ & 18.6 & 11.6 & 10.8 & 16.9 & 14.4 & 11.2 \\
Median & 490.0 & 482.0 & 485.0 & 494.0 & 488.0 & 500.0 \\
Range & 68.0 & 54.0 & 32.0 & 92.0 & 43.0 & 50.0 \\
\hline
\end{tabular}


blade is thicker along the back than along the cutting edge, and is likewise thicker at the crossguard than at the tip. Also, there is a fuller on each side of the blade. The thickness of the blade back and flat were determined to a large extent by the stamping and rolling processes that produced the blade blank, and so are not likely to vary significantly from one bayonet to another at the pre-finishing stage. However, the final thickness of the blade edge and the length, width and depth of the fullers, result from the grinding process that prepared the blade blank for the addition of the other components, and are more obviously going to differ from one bayonet to any of its peers, even those brought to completion by the same finisher. In the days before computer-controlled machining, such shaping of a groove to form a fuller at a machine, for example, was done essentially by hand and individual judgement. The judgements of the operators of the milling and grinding machines were thus, or so it would seem, the arbiters of the 'correct' dimensions for the fullers.

But, can a very small difference in the dimensions of a fuller make a noticeable difference to the weight of a bayonet? The single measurements of a fuller taken on a bayonet in a private collection are approximately $320 \mathrm{~mm}$ long $\times 8 \mathrm{~mm}$ wide $\times 3 \mathrm{~mm}$ deep. For arithmetical convenience, suppose that the depth is truly $4 \mathrm{~mm}$. If it is ignored that the fuller becomes shallower near the tip and the blade flat, the fuller can then be treated for the purpose of this paper as a groove of semi-circular cross section. The weight (W) is then given by Equation I,

$$
W=0.5 \times \pi r^{2} \times L \times \rho
$$

where $r$ and $L$ are the radius and length in $\mathrm{cm}$, respectively, and $\rho$ is the density of steel. The weight of steel removed to form this groove is approximately $64 \mathrm{~g}$. Let us suppose instead that there is a difference in the width measurement and the groove is actually $6 \mathrm{~mm}$ wide and $3 \mathrm{~mm}$ deep. The weight of steel removed to form this groove is approximately $36 \mathrm{~g}$. Thus a difference of approximately $28 \mathrm{~g}$ ( $\mathrm{I} \mathrm{Oz}$.) is incurred by going from a semi-circular cross-section groove of radius $3 \mathrm{~mm}$ to one of radius $4 \mathrm{~mm}$. There are two fullers on a blade, and the same result is derived if the I $\mathrm{mm}$ difference of radius is instead assigned as $0.5 \mathrm{~mm}$ to each of them. Similar results are obtained if the cross-section is assumed to be semi-elliptical. Regardless of the geometrical assumptions made, these numbers show that small differences in the dimensions of the fullers can have major impacts on the final weight of a bayonet.

As already noted, both the original 1908 specifications and their later amendments, and the 1929 Text Book of Small Arms, state how 'one-fourth' only of a batch of newly-made Patt. I907 bayonets was to be tested to establish if they fitted within the permitted parameters, including the weight range of $\mathrm{I} 6 \mathrm{oz}$. to I $8 \mathrm{oz}$. (454 to $5 \mathrm{IO} \mathrm{g}$ ). Indeed, any weighing done may have been of boxes of bayonets. If the bayonets were being examined by the batch method, that is to say, with samples being taken from a consignment for detailed testing rather than each individual bayonet being examined, then limited numbers of both highly overweight and underweight examples could easily escape notice by the inspector. For example, of the bayonets listed in Table 2, a total of I $_{5}$ (I0.6\%) are 
above the high end of the allowable weight range ( $18 \mathrm{oz} . ; 5 \mathrm{IO}$ ) and yet all were accepted. This incidentally provides indirect evidence of batch, rather than individual, inspections.

\section{Statistical Analysis}

It is known from probability theory that with a very large number of observations, a plot of the value of the observation ( $X$-axis) vs. frequency of that observation $(Y$-axis) gives a smooth, symmetrical bell-shaped curve, known as the normal distribution. Except for Vickers, possibly due to the small number of Vickers bayonet weights that were recorded, the data from each individual maker was shown to fit a normal distribution by the Shapiro-Wilk test. ${ }^{25}$ This is a mathematical test that is applied to a data-set to determine whether it approximates a normal distribution.

One attribute of a theoretical normal distribution is the coincidence of the mean (arithmetic average) value, the median value and the mode at the centre of the symmetrical distribution. The mode is that value that occurs with the greatest frequency, while the median is that value which is the middle data point when the weights are listed in order of magnitude. The combined data of Table 2 has a mean at 493.I g, a median value of $494.0 \mathrm{~g}$, a mode at $482.0 \mathrm{~g}$ and the standard deviation is $15.5 \mathrm{~g}$. Although the mean, median and mode values are not identical, the distribution passes the Shapiro-Wilk test and is therefore approximately normal. The combined data is also summarised visually in the histogram given in Figure 3, which shows a reasonably symmetric distribution about the mean. The $4 \mathrm{~g}$ bins, referred to in that figure, denote that the data points (the individual weights) were collected into groups that span a $4 \mathrm{~g}$ interval, i.e. $44^{8}-45^{\mathrm{I}}$ (no data points), 452-455 (two data points), 456-459 (two data points), 460-463 (one data point), ...480-483 (I 8 data points), ... 496-499 (I9 data points), .. 520-523 (no data points), ... etc.

Each maker, depending on the time-frame, presumably attempted to produce bayonets to meet either the I6.5 oz. (468 g) mean weight derived from the Patt. I907 initial

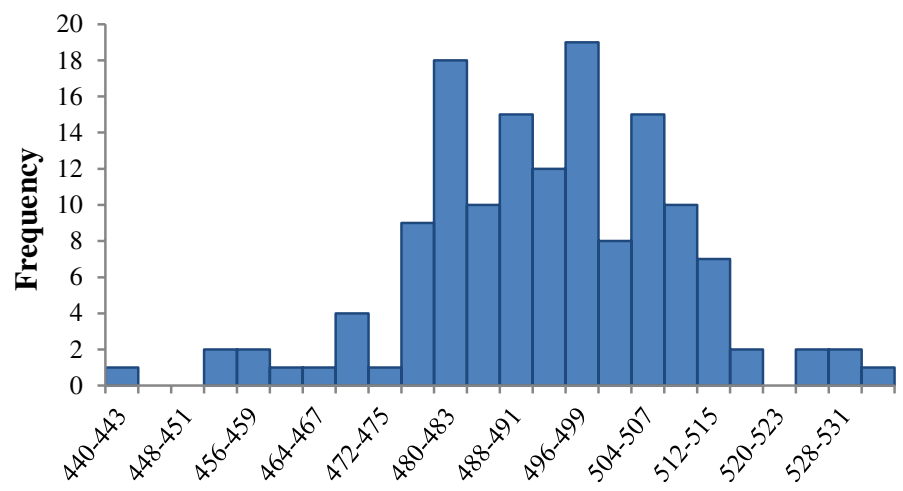

Bayonet Weights (4 $\mathrm{g}$ bins)

Figure 3. Frequency plot of bayonet weights. 
specification or the $17 \mathrm{Oz}$. $(482 \mathrm{~g})$ mean weight from the later specifications. Inevitable differences of finishing led to bayonet weights that were clustered around the target value, both above and below.

The matching of datasets to approximately normal distributions has a second interesting consequence, which we detail below.

A further mathematical attribute of a normal distribution is that about $99.7 \%$ of observations occur within plus and minus three standard deviations $\left( \pm_{3} \sigma\right)$ of the mean $(M) .{ }^{26}$ So the weights of virtually all $(99.7 \%)$ of the bayonets, produced by any manufacturer, will be bracketed by the values $(M+3 \sigma) g$ and $(M-3 \sigma) g$, where $M$ and $\sigma$ are determined from the data of that manufacturer. To maximise their profits, the makers had only to set up operations such that the condition of equation 2 was met.

$$
(M-3 \sigma) g=\text { lowest acceptable weight }
$$

The issue for the manufacturers was then to determine appropriate values for these variables (mean, standard deviation and lowest acceptable weight). Setting target values for the mean weight and lowest acceptable weight would allow a value for the required standard deviation to be calculated. If we take the values for the specification during the highest rate of production (the I9I4-I9I8 period), we have the mean weight $(M)$ set at $482 \mathrm{~g}$ ( $\mathrm{I} 7 \mathrm{Oz}$.) and the lowest acceptable weight set at $454 \mathrm{~g}$ ( $16 \mathrm{oz}$.); the standard deviation, $\sigma,{ }^{27}$ is then calculated to be $9.3 \mathrm{~g}$ (0.33 oz.).

However, making a new product with an allowed weight range of I6-I8 oz. was not necessarily a straightforward enterprise in terms of quality control, especially under the pressure of war-time production demands. Note from Table 3 for instance, that none of the manufacturers was able to achieve a standard deviation as low as $9.3 \mathrm{~g}$. So a value of $\sigma$ that was likely to be achievable had to be known, or if not known then it would have to be estimated from prior bayonet-making or sword-making experience. All of the manufacturers, except Chapman and Vickers, had previously produced Patt. I888 and I 903 bayonets under government contract and may have been able to estimate an expected value of $\sigma .{ }^{28}$ Chapman and Vickers on the other hand seem to have been newcomers to the large-scale manufacture of edged blades (a connection between the J. A. Chapman Ltd. of Yorkshire and the W. Chapman of Staffordshire who had manufactured India Pattern sword-bayonets during the Napoleonic Wars, ${ }^{29}$ is possible but unproven) which presumably explains why they were apparently contracted to produce only a limited number of Patt. 1907 bayonets. ${ }^{30}$

As it is, the $(M-3 \sigma) g$ values calculated for each of the makers are given in Table 4 and it can be seen that only Wilkinson has actually come close to meeting the requirement of Equation 2 (see following discussion).. There is no direct evidence that such a statistical

TABLE 4.

VALUE OF $(M \sigma-3 \Sigma)$ IN G, FOR EACH MAKER

\begin{tabular}{lcccccc}
\hline Maker & Chapman & Enfield & Mole & Sanderson & Vickers & Wilkinson \\
\hline$(M-3 \sigma)$ & 434.0 & 448.6 & 454.0 & 442.3 & 438.1 & 466.9 \\
\hline
\end{tabular}


analysis was actually performed by Wilkinson, or by any of the other bayonet makers. However, it may reasonably be assumed from at least those makers experienced in making bladed weapons to meet contract specifications. In which case our observation here that 48 samples of bayonets made by Wilkinson have a mean weight $(M)$ of $500.5 \mathrm{~g}$ and a standard deviation $(\sigma)$ of II.2 g, to yield an $(M-3 \sigma) \mathrm{g}$ value of $466.9 \mathrm{~g}$ may well provide indirect evidence for such a procedure. We might reasonably infer that Wilkinson used their previous extensive experience as a commercial bayonet maker, having made about I08,000 Patt. I 888 bayonets, as well as other bladed weapons in earlier times, to ensure their compliance with the desired weight specification for the Patt. I907 bayonets they were now producing. The theory of the normal distribution had been well-known since about $\mathrm{I} 835$, and statistical analysis applied to industrial production had been performed since at least the early I900's. ${ }^{3 \mathrm{I}}$ The marked differences between the distribution of the weights of the Wilkinson bayonets and those of the five other makers are evident in the values summarised in Tables 3 and 4 . If these differences are not the result of deliberate manufacturing manipulations, then they are the results of random fluctuations of manufacture. The proximity of $466.9 \mathrm{~g}$ for the $(M-3 \sigma) \mathrm{g}$ value to the weight of $468 \mathrm{~g}$ would then have to be regarded as purely coincidental.

With regard to the other makers, these are fairly closely matched in terms of their production values, although the relative inexperience of Chapman and Vickers at bayonet-making is duly revealed in their much lower values of $(M-3 \sigma) \mathrm{g}$ compared to even Enfield and Sanderson. That said, the failure of the Patt. I907 bayonet makers other than Wilkinson, to meet the condition of Equation 2 is, nonetheless, somewhat surprising given how we assume that as experienced metalsmiths working in other traditions, they would have some grasp of quantifying the metal amount required to make the necessary number of blanks at a set size.

We believe that there is an additional, very reasonable and compelling explanation for the weights given in Table 2 to be noticeably skewed to the higher end of the allowed weight range. This derives from the apparent mismatch between the design of the post-January I9I6 Patt. I907 bayonet and the allowed weight range given in the amended manufacturing specifications of I9IO and I9I4. As noted above, the highest production was in the wartime (I9I4-I9I8) period, to meet the 454-5 IO g (I6-I8 oz.) weight range, with a mean at $482 \mathrm{~g}$ ( $\mathrm{I} 7 \mathrm{Oz}$.) that was set in I9IO and maintained in I9I4. However, until near the end of I9I3, these weights were for the initial bayonet design with a hooked quillon but without a clearance hole. The bayonet design was then changed to eliminate the hooked quillon, but the allowed weight range was not changed. ${ }^{32}$ A further design change was implemented to add a clearance hole to the pommel, but again the allowed weight range was not changed. 33

As described in Methodology, removing the hooked quillon (I9I3) and adding a clearance hole (I9I6) reduces the weight by an estimated I4 g (0.5 Oz.). This meant that the very same manufacturing practice that in early $\mathrm{I} 9 \mathrm{I} 3 \mathrm{had}$ been set up to produce bayonets in the $454-5 \mathrm{IO} g$ (I6-I8 oz.) weight range, with a mean at about $482 \mathrm{~g}$ (I7 Oz.) would now produce in I9I6 and onwards, bayonets that were about I $4 \mathrm{~g}(0.5 \mathrm{Oz}$.) lighter. Bayonets at 
the lower weight end might now be judged 'inferior' to the sealed pattern and therefore neither accepted nor paid for.

Therefore, to compensate for this lost I4 g the makers would have had to increase the weight of the blade blanks by I4 $\mathrm{g}$ as if they were producing bayonets with a weight range of $468-524 \mathrm{~g}$ (I6.5-I8.5 oz.) and a mean of $496 \mathrm{~g}$ (I7.5 Oz.). For maximum financial efficiency, i.e. profit, the required values for a normal distribution of bayonet weights now are mean, $M=496 \mathrm{~g}$, lowest acceptable weight is $(M-3 \sigma) \mathrm{g}=468 \mathrm{~g}$ while the higher bound is $(M+3 \sigma) \mathrm{g}=524 \mathrm{~g}$.

What is of interest here is to summarise some of the data given throughout this text with specific reference to those bayonets made by Wilkinson. As we can see from Table 2, the heaviest Wilkinson bayonets in our sample are two at $524 \mathrm{~g}$ each; from Table 3 the Wilkinson bayonets have a mean weight of $500.5 \mathrm{~g}$; from Table 4 the Wilkinson bayonets give a value for $(M-3 \sigma) g$ of $466.9 \mathrm{~g}$. Comparing these numbers to the equivalent data from the other makers provides very strong presumptive evidence that Wilkinson, at least, did in fact perform a statistical analysis, followed by manufacturing manipulations to meet the government specifications.

As deduced from Table I, we are looking at a scant sample of the output of the individual makers, which ranged from 10,000 to 2,360,000 bayonets. We accept that we are dealing here with small datasets. Also, the data was obtained from 'convenience' sampling, i.e. the data that was easiest to access (from collectors and sellers) was used. Therefore, this was not true probability-based sampling, where every Patt. I907 still in existence had an equal chance of being sampled and it is not considered to be truly random sampling. As such, there is the possibility that analysis of larger datasets would yield different results than those presented here. If this sample of bayonets is a reasonable representation of the population of all Patt. 1907 bayonets, then a $95 \%$ confidence interval of the true proportion of overweight bayonets can be calculated as shown in Equation 3

$$
p=\hat{p} \pm z^{*}[\hat{p}(1-\hat{p}) / n]^{1 / 2}
$$

where $p=$ proportion of 'overweight' bayonets in population, $\hat{p}=$ proportion of 'overweight' bayonets in sample $(0.76 ; 76 \%)$ and the multiplier $z^{*}=$ I.96. This gives $p=0.76 \pm 0.07$. Thus if the sampling was repeated Ioo times for $\mathrm{I} 42$ different bayonets each time, we could be confident that the proportion of 'overweight' bayonets would be found within the range 0.69 to 0.83 on 95 of those occasions. This interval falls above $50 \%$, lending evidence to the speculation that the Patt. I907 bayonets were intentionally made to be overweight.

However, due to possible biasses ('survival of the fittest'; failure of some sellers to respond to requests for information; optimum condition of bayonets selected by collectors, etc.), further study to gain more information would be helpful to obtain a definitive result. 


\section{Conclusions}

In retrospect, it is perhaps not surprising that the bayonets surveyed for this study are almost all above the mid-point of the weight-range specification. Although the blades for these bayonets were all made using machinery that could produce thousands of more or less identically-sized blanks of a more or less identical weight, they were hand-finished to produce an item that conformed to the required official specifications. It was at the first step in this hand-finishing stage, the grinding of the blades to the required shape and form, that noticeable variations would be introduced into what had once been essentially identical blanks. Even so, the various makers of the Patt. 1907 bayonet were expected to produce finished bayonets that conformed closely to the official specifications with regards to their length, weight, and other details. What our study has shown, however, is that an unexpectedly high number of Patt. I907 bayonets are in fact significantly over the mid-point weights (I6.5 Oz.; $468 \mathrm{~g}$ and I7 Oz.; $482 \mathrm{~g}$ ) of the acceptable ranges as indicated in the various official sources.

This is unlikely to have been accidental and suggests that the various makers deliberately produced blade blanks that were overweight in the first instance to compensate for any being underweight at the end of the finishing stage. This over-compensation factor is quite understandable in the case of those private firms contracted to make Patt. I907 bayonets, who would be paid only by results. For these private makers, financial factors were pre-eminent, and all would have had a certain level of expertise in the matter of product-costing to ensure minimal loss and maximal profit. Thus they shared a clear need to ensure that all of their finished products met the official specifications and so could not be rejected for whatever reason. In which case it would seem logical to cost for, and produce, overweight blanks as a matter of course to ensure a finished bayonet that could not be rejected for being underweight. Nevertheless, it is noticeable how some makers, for example Wilkinson, managed to produce finished items that, while usually 'overweight', did so within generally consistent figures. However, the production of 'overweight' Patt. I907 bayonets is not so easily explained in the case of the British government's own manufacturer, the RSAF. In their case we might assume that the matter of profit and loss was of less importance, and that whether or not a bayonet conformed exactly to the required standard was of no real matter; the weight variations then result simply from a lack of detailed quality control. With these issues, combined perhaps with the pressures of meeting wartime quotas, the observed wide variation in weights was almost certain to occur.

\section{Acknowledgements}

Thanks are due to Christopher J. McDonald, Michael James, Terrence Lee (fellow-collectors) and Edward Purvis (National Army Museum, London), who kindly provided the weights of bayonets in their collections. The majority of the remainder were generously provided by on-line sellers, who are too numerous to mention individually. 
Photographs of a Patt. 1907 bayonet with hooked quillon but without a clearance hole (Figure I(a) and (b)) and of a Patt. 1907 bayonet without hooked quillon but with a clearance hole (Figure 2) were provided by one author (J. B.) and Dr Christopher J. McDonald (Department of Political Science, Lincoln Land Community College, Springfield, Illinois, USA), respectively.

Dr C. J. McDonald is also thanked for a critical review of the manuscript, comments regarding the overall importance of bayonet weight and for bringing the Text Book of Small Arms to the attention of the authors.

We are grateful also to the comments and suggestions made by the anonymous reviewers, and to Stuart Ivinson, Librarian at the Royal Armouries, Leeds, for supplying us with copies of the relevant official specifications.

\section{Notes}

${ }^{1}$ List of Changes in British War Material in Relation to Edged Weapons, Firearms and Associated Ammunition and Accoutrements, para. I4I70 January 30, I908.

${ }^{2}$ Specification No. S.A./319, Sword-bayonet, Pattern I907 (Mark I) for Rifles, short, M.L.E. Specification to govern manufacture and inspection, Approved, March 9, 1908. The allowed blade length range and overall length range given here were carried over unchanged in the revisions (Specification No. S.A./3I9/A, approved June 6, I9Io and Specification No. S.A./3I9/B, approved May 8, I9I4) of I9Io and I9I4, respectively. The initial allowed weight range of the finished bayonet, I5.5-I7.5 oz. in Specification No. S.A./3I9, was changed to I $6-\mathrm{I} 8 \mathrm{oz}$. for the revisions of I9I0 and I9I4. However, these considerations would change neither our overall results nor the conclusions drawn from those results.

3 Patent Application No. I4, I6 3 for the nose-cap boss system used for attaching a bayonet to the SMLE, as issued on July II, and accepted August I7, I90I, refers to 'the hole in the cross' which was a common term for the crosspiece or crossguard of edged weapons. It is, however, described as the 'cross-piece' in Specification S.A. No. S.A./3I9 of 1908 for the Patt. I 907 sword-bayonet and in the later amended versions we have seen namely those, issued as amended in I9Io and I9I4. Reference works of the later I9th century use often the terms 'crosspiece' and 'cross-piece' for the part in question, but the expressions 'cross-guard' and 'crossguard' were also in common use: see, e.g. C. Boutell's translation of J. P. Lacombe, Arms and Armour in Antiquity and the Middle Ages (London, I869), p. I73, and R. F. Burton, The Book of the Sword (London, I884), p. I25. Similarly, the book by I. D. Skennerton and R. Richardson, British and Commonwealth Bayonets, (Australia, I984) likewise uses both terms, even when discussing the Patt. 1907 bayonet, as at p. I87, where reference is made to its 'crosspiece', and at p. 20I, where they employ 'crossguard' in describing a 'Prototype Wirebreaker bayonet' based on a Patt. 1907 bayonet. As it is, a check of several modern bayonet reference works indicates that 'crossguard' is the most commonly used term today and so we have chosen to follow this practice here and throughout the text.

${ }^{4}$ See footnote 2

5 See footnote 2

${ }^{6}$ A. Hutton, Fixed Bayonets: A Complete System of Fence for the British Magazine Rifle (London: William Clowes \& Sons, I890), p. I25, and I3I-I 32 .

7 E. G. B. Reynolds, The Lee-Enfield Rifle (London: Herbert Jenkins, I960), p. 2I2, Appendix C, Rifles and Carbines in the British Service in I9IO.

${ }^{8}$ F. Strother, The World's Works, Vol. XXXI, Nov. I9I 5 to Apr. I9I6, ed. W. H. Page and A. W. Page, (Garden City \& New York: Doubleday, Page \& Company, I9I6), p. 99.

9 See above footnote.

to See footnote 8

II List of Changes, para. I6755 October 29, I9I3.

${ }^{12}$ List of Changes, para. I7692 January 5, I9I6; February 23, I916.

${ }^{13} \mathrm{https}$ ://I9I4-I9I8.invisionzone.com/forums/index. php?/topic/25I223-heavily-stamped-pr907/ [accessed 26 June 17 ]; Dr C. J. McDonald is thanked for reporting the existence of this piece.

${ }^{14}$ See footnote I

Is Text Book of Small Arms, (London: His Majesty's Stationery Office, I929), p. 84.

${ }^{16}$ See footnote 2

17 ibid., p. 85 .

${ }^{18}$ ibid., p. 85 .

I9 ibid., p. 86.

${ }^{20}$ CRC Handbook of Chemistry \& Physics, 59th Edn (Boca Raton, FL: CRC Press, I978), Table F-329.

${ }^{21}$ CRC Handbook of Chemistry \& Physics, Table D-223. 
22 Private communication, August 24, 2015 from International Military Antiques (http//:www.ima-usa. com).

23 I. D. Skennerton and R. Richardson, British o Commonwealth Bayonets, (published privately) (Australia: Margate, I984), p. I9I.

${ }^{24}$ I. D. Skennerton and R. Richardson, Australian Service Bayonets, (published privately) (Australia: Margate, I976), p. 44.

25 S. S. Shapiro and M. B. Wilk, An Analysis of Variance Test for Normality (complete samples), (Biometrika, I965), 52, 3 \& 4, p. 59I-6II.

$26 \mathrm{~J}$. Topping, Errors of Observation and their treatment (London: Chapman and Hall Ltd., I962), p. 6I.

27 We are aware of the difference between the use of $\sigma$ for the standard deviation of the whole population and the use of $s$ for the standard deviation of a sample taken from the population. The standard deviation, $\sigma$, was introduced in the discussion of a normal distribution of the whole population of bayonets made by a manufacturer. Although the standard deviations of the datasets presented here should be more correctly represented by $s$, we have chosen to keep the $\sigma$ notation to avoid confusion.

28 I. D. Skennerton and R. Richardson, British \& Commonwealth Bayonets, p. 165-8, I70.

29 ibid., p. 55, 57.

$3^{\circ} \mathrm{J}$. A. Chapman Ltd. was a contractor for the conversion of Patt. I888 sword-bayonets to Patt. 1903; however, that involved only pommel \& crossguard work and there was no blade-making required (ibid., p. I82). Also, Vickers Ltd. had made about 1500 of the Patt. I9I3 sword-bayonets in I9I7 (ibid., p. I90).

${ }^{1}$ Student, The Probable Error of a Mean (Biometrika, I908), 6, p. I-25.

${ }^{32}$ See footnote II.

33 See footnote I2.

\section{Notes on Contributor}

John M. Ballard received a PhD in organic chemistry from the University of London (UK), and spent his career as a mass spectrometrist in the environmental, polymer and pharmaceutical industries. Since retiring, he has pursued his interests in the Great War.

Julian Bennett, a Fellow of the Society of Antiquaries of London, received a $\mathrm{PhD}$ in archaeology from the University of Newcastle upon Tyne (UK), and is currently Associate Professor in the Department of Archaeology at Bilkent University in Ankara, Turkey. His interests are in Roman archaeology and the bayonets and other artefacts of the Great War.

Correspondence to: John M. Ballard.Email: johnballard@comcast.net 